\title{
Comparison of intraocular pressure measurement with Schiotz tonometer and Tono-Pen Vet tonometer in healthy dogs
}

\author{
Karolina Wrześniewska, Jacek Madany, Dagmara Winiarczyk \\ Department and Clinic of Animal Internal Diseases, \\ Faculty of Veterinary Medicine, \\ University of Life Sciences, 20-612 Lublin, Poland \\ karola.wrzesniewska@gmail.com
}

Received: December 18, 2017

Accepted: April 30, 2018

\begin{abstract}
Introduction: Measurement of intraocular pressure (IOP) in dogs has high diagnostic value because of the possibility of detecting ocular and systemic diseases. Various types of tonometers are available for this measurement in small animal practice. The aim of the study was to compare the IOP values measured with Schiotz and Tono-Pen Vet tonometers in healthy dogs. Clinical diagnostic usefulness of both models was also evaluated. Material and Methods: The examination was performed in 62 eyes in 31 clinically healthy dogs of different races, gender, and ages. Results: The values for intraocular pressure obtained with Schiotz tonometer were in the range of 12 to $24 \mathrm{mmHg}$, with the mean of $16.3 \pm 2.1 \mathrm{mmHg}$. The intraocular pressure measured with Tono-Pen Vet tonometer was in the range of 11-25 $\mathrm{mmHg}$, with a mean of $18.1 \pm 3.8 \mathrm{mmHg}$. The mean results of measurements taken using the two tonometers differed statistically significantly, the difference being $1.79 \mathrm{mmHg}$ and the higher values being read from the Tono-Pen Vet tonometer. Conclusion: Correlation coefficients calculated for the results obtained in the right and left eyes using two tonometers indicated highly correlative relationships between the results. The study shows that both tonometers can be advantageously used in clinical practice to measure intraocular pressure in dogs.
\end{abstract}

Keywords: dogs, eyes, intraocular pressure, applanation tonometer, impression tonometer.

\section{Introduction}

Intraocular pressure (IOP) and its measurement are the basic methods used in standard ophthalmic examination. It is used to assess both acute and chronic disorders like acute angle closure or monitoring chronic disease like advanced glaucoma. IOP fluctuation is regulated by aqueous humour created in the ciliary body, being stabilised by the constant balance between production and outflow of humour mainly through the trabecular meshwork to the ciliary veins.

The pressure exerted by aqueous humour provides the correct tonus to the eyeball and the right hydration of the optic media: cornea, lens, and vitreous body, which ensures transparency and regularity of curvature. IOP greatly depends on balance between the production of aqueous humour and the possibility of its outflow, depending hence on the construction and efficiency of intraocular structures that take part in this process. Other factors also have an effect on IOP in dogs including breed, age, time of day, sedatives, anaesthetics, the method of measurement, and compression on the neck, head, and eye socket area during the test $(10,12)$.

IOP changes in dogs are caused by diseases of the internal structures of the eyeball, or may be a symptom of systemic diseases. The measurement of intraocular pressure therefore has high diagnostic value. It helps to diagnose injuries and atrophy of the eye and ophthalmic diseases, such as glaucoma, uveitis, and buphthalmia. It is supposed that changes in intraocular pressure can accompany general diseases, including diseases of the heart and kidneys, and parasitic diseases. These suspicions increase the scope of indications for measuring intraocular 
pressure $(4,10,11)$. For these reasons, the valuable and reliable measurement of intraocular pressure remains a major practical challenge.

Direct measurement using paracentesis and cannulation of the anterior chamber of the eye is the most reliable method of IOP measurement. It is one of the methods that provide the most objective results, but its invasiveness makes it impossible to apply in clinical practice. Therefore, in everyday practice indirect non-invasive methods are used. Currently, the IOP measurement method known as tonometry can be performed using three methods. The first one is the impression (invaginating) method with the use of a Schiotz tonometer. The second is the applanation (flattening) method with the use of tonometers such as Tono-Pen Vet, Tono-Pen XL, and air puff types. The third is the rebound (impaction) method in which the Icare TonoVet is used. In human medicine the Goldmann applanation tonometer (GAT) is currently accepted as the standard-setting tonometer. Unfortunately, measuring with the GAT is not possible with veterinary patients owing to their lack of co-operation.

In small animal ophthalmology practice, the impression and applanation methods are most often used. The first is based on measuring invagination of the cornea under its load with fixed and known force. The Schiotz tonometer uses this method. It shows the result on a scale of $1-20$, which is converted into $\mathrm{mmHg}$ according to table. This tonometer is used in human and veterinary medicine, and even though it is the oldest method it still has its supporters $(6,14,15)$. The Tono-Pen Vet is an applanation tonometer. It is an electronic device that works by measuring the force required to flatten the cornea. It analyses the value of this force and the time of its operation. The result, calculated in $\mathrm{mmHg}$, appears on its screen as the mean value of three to six touches of the cornea $(11,18)$.

The aim of the study was to compare intraocular pressure measured with Schiotz and Tono-Pen Vet tonometers in clinically healthy dogs and to evaluate their diagnostic usefulness in small animal practice.

\section{Material and Methods}

The study was conducted in dogs treated at the Clinical Department of Internal Medicine of Animals at the Faculty of Veterinary Medicine of the University of Life Sciences in Lublin, with the consent of their owners. The dogs were covered by preventive and control programmes carried out in the clinic. IOP values were measured in 62 eyes in 31 mongrels and dogs of different races, male and female, in the ratio $13: 18$, between 4 months and 13 years old, after clinical and ophthalmic examinations. The dogs had no clinical or ophthalmic problems.
Before measuring the pressure, 1-2 drops of $0.5 \%$ Alcaine (Alcon, USA) were administered to both conjunctival sacs for local anaesthesia of the cornea. All the measurements were performed by the same person and in accordance with the instructions for the use of the tonometers. The dogs were held by an assistant in the recommended way to guarantee safe and effective measurements. The intraocular pressure was measured firstly in the right and then in the left eye, using the Schiotz tonometer (Riester, Germany) with the vertical scale and a weight of $7.5 \mathrm{~g}$ and then with the Tono-Pen Vet tonometer (Reichert, USA). Each measurement was performed three times and the mean of three results was calculated and taken as the final outcome. The Schiotz tonometer was dismantled after each test and its parts were disinfected and stored until the next test in the supplied airtight bag. The Tono-Pen Vet tonometer was fitted with a sterile rubber tip on the head which was removed after the examination and the device was stored in the closed container provided by the manufacturer.

The mean values of IOP measurements obtained using the Schiotz and Tono-Pen Vet tonometers were compared statistically. The significance of differences was calculated using the paired $t$-test, and the correlation coefficient was derived using the Pearson method with $\mathrm{P} \leq 0.05$. The calculations used the Statistica 10.0 programme (StatSoft, Poland) and an Excel spreadsheet.

\section{Results}

The results of canine intraocular pressure measurements taken with two tonometers are shown in Table 1.

In healthy dogs, the normal values of intraocular pressure are in the range of $10-21 \mathrm{mmHg}(4,10)$. Intraocular pressure measured with the Schiotz tonometer varied in individual dogs from 12 to $24 \mathrm{mmHg}$, with a mean of $16.3 \pm 2.1 \mathrm{mmHg}$, while pressure measured with Tono-Pen Vet tonometer ranged from 11 to $25 \mathrm{mmHg}$, with a mean of 18.1 $\pm 3.8 \mathrm{~mm} \mathrm{Hg}$. The mean values of intraocular pressure obtained using the two methods were statistically different, but this difference was only $1.79 \mathrm{mmHg}$, with values higher for the Tono-Pen Vet tonometer.

The correlation coefficient for the results obtained in the left and right eyes in the measurement with the Schiotz tonometer was 0.62687, which indicated a highly correlative relationship between the results (Fig. 1).

Correlation coefficient for the results obtained in the left and right eyes during the measurements with Tono-Pen Vet was 0.89422, which also proved a highly correlative relationship between the results (Fig. 2). 
Table 1. Values of IOP in mmHg measured by Schiotz and Tono-Pen Vet tonometers in healthy eyes of conscious dogs (31 dogs, 62 eyes)

\begin{tabular}{|c|c|c|c|c|c|c|}
\hline Animal no. & $\begin{array}{l}\text { Schiotz } \\
\text { tonometer } \\
\text { reading OD }\end{array}$ & $\begin{array}{l}\text { Schiotz } \\
\text { tonometer } \\
\text { reading OS }\end{array}$ & $\begin{array}{l}\text { Mean Schiotz } \\
\text { tonometer } \\
\text { reading }\end{array}$ & $\begin{array}{l}\text { Tono-Pen Vet } \\
\text { reading OD }\end{array}$ & $\begin{array}{l}\text { Tono-Pen Vet } \\
\text { reading OS }\end{array}$ & $\begin{array}{l}\text { Mean Tono-Pen } \\
\text { Vet reading }\end{array}$ \\
\hline 1 & 16.0 & 20.0 & 18.0 & 15.0 & 18.0 & 16.5 \\
\hline 2 & 15.0 & 16.0 & 15.5 & 17.0 & 18.0 & 17.5 \\
\hline 3 & 16.0 & 16.0 & 16.0 & 20.0 & 20.0 & 20.0 \\
\hline 4 & 19.0 & 16.0 & 17.5 & 17.0 & 15.0 & 16.0 \\
\hline 5 & 24.0 & 22.0 & 23.0 & 22.0 & 23.0 & 22.5 \\
\hline 6 & 19.0 & 18.0 & 18.5 & 14.0 & 12.0 & 13.0 \\
\hline 7 & 16.0 & 17.0 & 16.5 & 13.0 & 11.0 & 12.0 \\
\hline 8 & 18.0 & 17.0 & 17.5 & 18.0 & 19.0 & 18.5 \\
\hline 9 & 16.0 & 18.0 & 17.0 & 24.0 & 21.0 & 22.5 \\
\hline 10 & 18.0 & 17.0 & 17.5 & 22.0 & 22.0 & 22.0 \\
\hline 11 & 19.0 & 16.0 & 17.5 & 20.0 & 23.0 & 21.5 \\
\hline 12 & 21.0 & 18.0 & 19.5 & 22.0 & 19.0 & 20.5 \\
\hline 13 & 14.0 & 14.0 & 14.0 & 23.0 & 21.0 & 22.0 \\
\hline 14 & 16.0 & 18.0 & 17.0 & 19.0 & 18.0 & 18.5 \\
\hline 15 & 12.0 & 13.0 & 12.5 & 25.0 & 22.0 & 23.5 \\
\hline 16 & 14.0 & 17.0 & 15.5 & 17.0 & 17.0 & 17.0 \\
\hline 17 & 16.0 & 14.0 & 15.0 & 17.0 & 15.0 & 16.0 \\
\hline 18 & 18.0 & 17.0 & 17.5 & 21.0 & 22.0 & 21.5 \\
\hline 19 & 18.0 & 16.0 & 17.0 & 17.0 & 16.0 & 16.5 \\
\hline 20 & 12.0 & 16.0 & 14.0 & 18.0 & 16.0 & 17.0 \\
\hline 21 & 16.0 & 20.0 & 18.0 & 16.0 & 13.0 & 14.5 \\
\hline 22 & 18.0 & 16.0 & 17.0 & 17.0 & 18.0 & 17.5 \\
\hline 23 & 16.0 & 17.0 & 16.5 & 22.0 & 21.0 & 21.5 \\
\hline 24 & 14.0 & 13.0 & 13.5 & 12.0 & 11.0 & 11.5 \\
\hline 25 & 12.0 & 14.0 & 13.0 & 16.0 & 16.0 & 16.0 \\
\hline 26 & 18.0 & 16.0 & 17.0 & 16.0 & 12.0 & 14.0 \\
\hline 27 & 15.0 & 16.0 & 15.5 & 11.0 & 13.0 & 12.0 \\
\hline 28 & 16.0 & 15.0 & 15.5 & 24.0 & 22.0 & 23.0 \\
\hline 29 & 13.0 & 14.0 & 13.5 & 23.0 & 23.0 & 23.0 \\
\hline 30 & 14.0 & 16.0 & 15.0 & 23.0 & 21.0 & 22.0 \\
\hline 31 & 14.0 & 16.0 & 15.0 & 12.0 & 12.0 & 12.0 \\
\hline Mean $\pm \mathrm{SD}$ & $16.2 \pm 2.7^{\mathrm{a}}$ & $16.4 \pm 2.0^{\mathrm{a}}$ & $16.3 \pm 2.1^{\mathrm{a}}$ & $18.5 \pm 3.9^{b}$ & $17.7 \pm 3.9^{b}$ & $18.1 \pm 3.8^{\mathrm{b}}$ \\
\hline Minimum & 12.0 & 13.0 & 12.5 & 11.0 & 11.0 & 11.5 \\
\hline Maximum & 24.0 & 22.0 & 23.0 & 25.0 & 23.0 & 23.5 \\
\hline
\end{tabular}

Mean \pm SD: different superscript letters indicate significant differences

*Three IOP readings were measured with the Schiotz tonometer and Tono-Pen Vet tonometer and the mean was calculated $\mathrm{OD}$ - right eye

OS - left eye

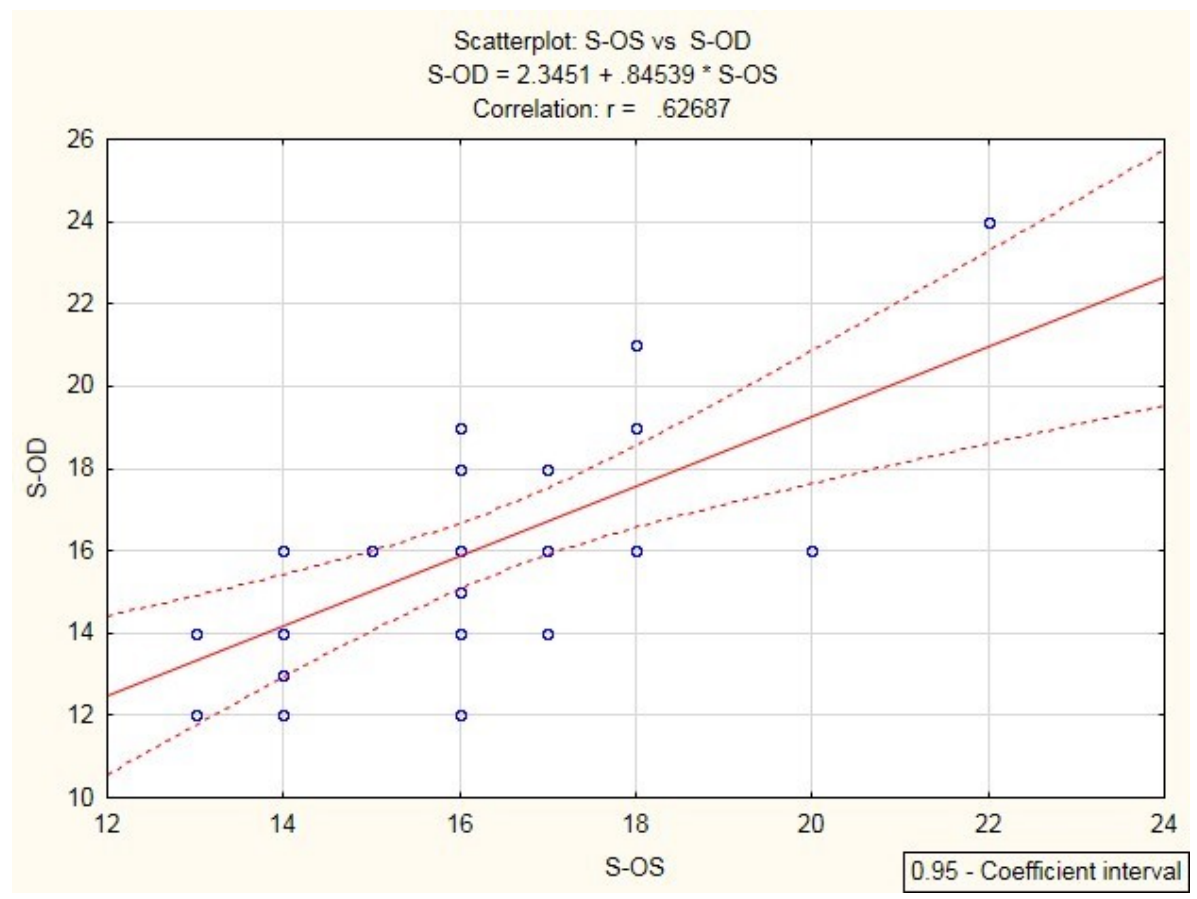

Fig. 1. Intraocular pressure (IOP) measurement comparison in $\mathrm{mmHg}$ between OS and OD in 31 dogs (Schiotz tonometry) 


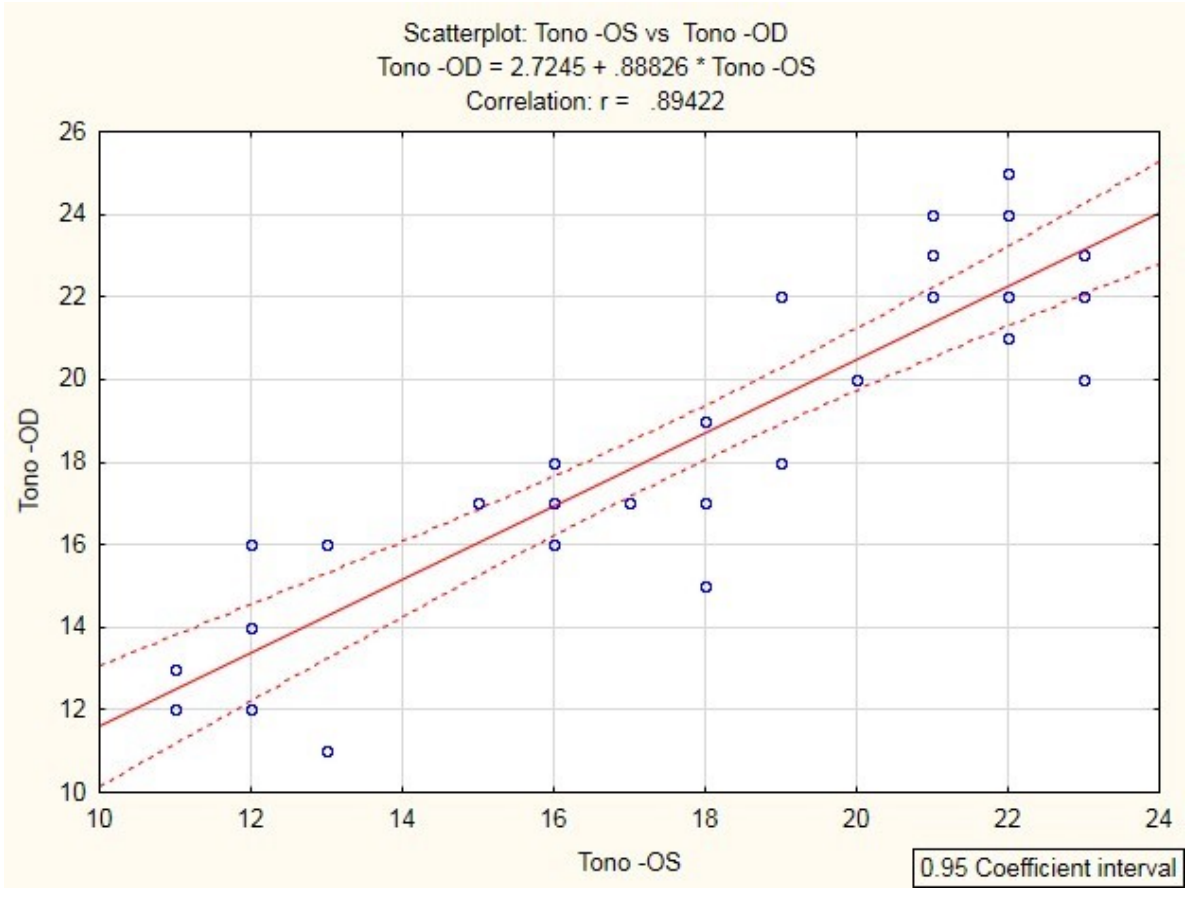

Fig. 2. Intraocular pressure (IOP) measurement comparison in $\mathrm{mmHg}$ between OS and OD in 31 dogs (Tono-Pen Vet tonometry)

\section{Discussion}

In recent years, some new types of tonometers have been introduced into ophthalmic diagnostics. A modern tonometer should be easy to use, give reliable and repeatable results, and cause minimum possible discomfort to the patient during the test. In humans, all new instruments are compared with the Goldmann applanation tonometer which is the standard-setter in the measurement of intraocular pressure $(5,9,19,20)$. In veterinary medicine, there is no gold standard, so all available types of hand-held tonometers are used. The Schiotz impression tonometer is popular, but we also use electronic applanation Tono-Pen Vet-type tonometers and rebound Tono Vettype versions $(7,8,18)$.

The study compared the results of intraocular pressure measurements taken with the two tonometers Schiotz and Tono-Pen Vet and evaluated their clinical usefulness in relation to benefits and disadvantages. Even though it is the oldest, the Schiotz tonometer still remains in use with animals. Nowadays it is very rarely used in humans, having been replaced be applanation tonometry and non-contact methods like air-puff tonometry. It can be still used in particular cases like post keratoplasty patients (3). According to our findings, it is also used in veterinary medicine in many centres dealing with small animal ophthalmology; however, recent studies on its use and results obtained with it are lacking.

In the study, the mean results for intraocular pressure obtained in healthy dogs using the Schiotz tonometer amounted to $16.3 \pm 2.1 \mathrm{mmHg}$. These results are very similar to those reported by other authors (18).
The mean IOP measurement result with the Tono-Pen Vet tonometer was slightly higher at $18.1 \pm 3.8 \mathrm{mmHg}$. These data are similar to the findings received previously by Gelatt et al. (4) and Miller et al. (13), and differ from them only by being $1.1 \pm 5.9 \mathrm{mmHg}$ higher and $1.4 \pm 4.0 \mathrm{mmHg}$ lower, respectively $(4,13)$. In our study, the difference between the mean results with the two types of tonometers was only $1.79 \mathrm{mmHg}$, but it turned out to be statistically significant. Some studies also found statistically significant differences between the assessed methods of IOP measuring (4). However, several studies have not found these differences $(1,13$, 17). Some works did not even assess them $(2,19,20)$. Standard deviation and result ranges are considered by some authors to have greater importance than differences in absolute numbers of $1-3 \mathrm{mmHg}$ in assessing the suitability of tonometers to measure IOP. From a clinical point of view, these differences seem to be permissible and acceptable, despite the existence of statistical differences $(2,4)$. The fact that should be stressed, though, is that the most important factor for IOP measurement in glaucoma is repeatability of the measurements.

The mean results of intraocular pressure obtained in the study and the results yielded from individual animals using two types of tonometers are within normal limits. It should be emphasised that there are no differences between the minimum and maximum values obtained in dogs using the two evaluated methods. The study also analysed the correlation between the results of pressure measured in the left and right eyes using both tonometers. The correlation coefficient was 0.62687 for the Schiotz tonometer and 0.89422 for Tono-Pen Vet. Both results indicate high 
correlation and in this are consistent with the observations of other authors $(1,16)$.

From the point of view of clinical practice, IOP measurement with the Schiotz impression tonometer is a simple and inexpensive method. The advantages of this method include good correlation of results, inexpensive maintenance, easy disinfection, and the low cost of device purchase. Compared to new devices, its disadvantage is greater difficulty in use with small animals, especially young and lively individuals, because in order to ensure accuracy of measurements the patient should remain still with the head held upright and the eyelids open for about 30-60 seconds. During the examination we must also be careful to avoid compression on the eyeball and neck, as this may influence measurement results.

Tono-Pen Vet is an applanation tonometer with electronic analysis of results. Its advantages include speed, ease of measurement, ability to perform test at each position of an animal, and an immediate reading on the LCD display. Moreover, it is small and light, and it is easy to store and preserve test sterility. This is achieved through the use of disposable rubber caps on the tonometer head. The disadvantages of this model include the need for frequent calibration and the significant cost of the equipment, which is about 10 times greater than the cost of a Schiotz tonometer. In both analysed models, previous local anaesthesia of the cornea is a necessary condition.

The results and clinical observations allow the conclusion that Schiotz tonometer and Tono-Pen Vet are diagnostically useful devices for measuring intraocular pressure in dogs. Both tonometers provide reliable and reproducible results and can be used for quick and efficient IOP measurements in dogs. Both models can therefore be effectively applied in daily clinical practice during clinical examinations of dogs. The Schiotz tonometer is the less financially burdensome alternative of the two, but because of its ease to use, lack of necessity for sterilisation, and shorter evaluation time, Tono-Pen Vet seems to be the more interesting option for everyday clinical use.

Conflict of Interests Statement: The authors declare that there is no conflict of interests regarding the publication of this article.

Financial Disclosure Statement: This study was supported by the University of Life Sciences in Lublin, Poland.

Animal Rights Statement: None required.

\section{References}

1. Andrade S.F., Palozzi R.J., Giuffrida R., de Campos R.J., de Campos Santos G., Fukui R.M.: Comparison of intraocular pressure measurements between the Tono-Pen XL® and Perkins ${ }^{\circledR}$ applanation tonometers in $\operatorname{dogs}$ and cats. Vet Ophthalmol 2012, 15, 14-20.

2. Christoffersen T., Holtedahl K., Ringberg U., Fors T.: Can the Tono-Pen replace the Schiotz tonometer in general practice? Scand J Prim Health Care 1998, 16, 238-241.

3. Estrovich I., Shen C., Chu Y., Downs J., Gardiner S., Straiko M., Mansberger S.: Schiotz tonometry accurately measures intraocular pressure in Boston type 1 keratoprosthesis eyes. Cornea 2015, 34, 682-685.

4. Gelatt K.N., MacKay E.O.: Distribution of intraocular pressure in dogs. Vet Ophthalmol 1998, 1, 109-114.

5. Iester M., Mermoud A., Achache F., Roy S.: New Tonopen XL: Comparison with the Goldmann tonometer. Eye 2001, 15, 52-58.

6. Kok M., Berendschot T., Hardus P.: Schiotz tonometry for glaucoma: are there simple alternatives? Trop Med Int Health 1998, 3, 210-213.

7. Knollinger A.M., La Croix N.C., Barrett P.M., Miller P.E.: Evaluation of a rebound tonometer for measuring intraocular pressure in dogs and horses. J Am Vet Med Assoc 2005, 227, 244-248.

8. Leiva M., Naranjo C., Peña M.T.: Comparison of the rebound tonometer (ICare) to the applanation tonometer (Tonopen XL) in normotensive dogs. Vet Ophthalmol 2006, 9, 17-21.

9. Li Y., Shi J., Duan X., Fan F.: Transpalpebral measurement of intraocular pressure using the Diaton tonometer versus standard Goldmann applanation tonometry. Graefes Arch Clin Exp Ophthalmol 2010, 248, 1765-1770.

10. Maggs D.J.: Basic diagnostic techniques. In: Slatter's Fundamentals of Veterinary Ophthalmology, edited by J. Garncarz, Elsevier Urban \& Partner, Wrocław, 2009, pp. 88-116.

11. Madany J., Clerc B., Pomorski Z.: Tonometria - mierzenie napięcia gałki ocznej. Mag Wet 1995, 4, 37-38.

12. Martin-Suárez E., Molleda C., Tardón R., Galán A., Gallardo J., Molleda J.: Diurnal variations of central corneal thickness and intraocular pressure in dogs from 8:00 am to 8:00 pm. Can Vet J 2014, 55, 361-365.

13. Miller P.E., Pickett J.P., Majors L.J., Kurzman I.D.: Clinical comparison of the Mackay-Marg and Tono-Pen applanation tonometer in the dog. Prog Vet Comp Ophthalmol 1991, 1, 171-176.

14. Ponka D., Baddar F.: Schiotz tonometry. Can Fam Physician 2014, 60, 252.

15. Stevens S.: How to measure intraocular pressure: Schiötz tonometry. Comm Eye Health J 2008, 21, 34.

16. Tonnu P.A., Ho T., Sharma K., White E., Bunce C., GarwayHeath D.: A comparison of four methods of tonometry: method agreement and interobserver variability. Br J Ophthalmol 2005, $89,847-850$.

17. Whitacre M.M., Emig M., Hassanein K.: The effect of Perkins, Tono-Pen, and Schiötz tonometry on intraocular pressure. Am J Ophthalmol 1991, 111, 59-64.

18. Von Spiessen L., Karck J., Rohn K., Meyer-Lindenberg A.: Clinical comparison of the TonoVet(®) rebound tonometer and the Tono-Pen $\operatorname{Vet}(\mathbb{R})$ applanation tonometer in dogs and cats with ocular disease: glaucoma or corneal pathology. Vet Ophthalmol 2015, 18, 20-27.

19. Yamamoto L.G., Young D.A.: Tonometry methods in the pediatric emergency department. Pediatr Emerg Care 2010, 26, 678-683.

20. Yilmaz I., Altan C., Ayqit E.D., Alaqoz C., Baz O., Ahmet S., Urvasizoqlu S., Yasa D., Demirok A.: Comparison of three methods of tonometry in normal subjects: Goldmann applanation tonometer, non-contact airpuff tonometer, and Tono-Pen XL. Clin Ophthalmol 2014, 8, 1069-1074. 